\title{
Systemic Family Therapy of Comorbidity of Anxiety and Depression with Epilepsy in Adolescents
}

\author{
Jing $\mathrm{Li}^{1}$, Xuefeng Wang ${ }^{2}$, Huaqing Meng ${ }^{1}$, Kebin Zeng ${ }^{2}$, Fengying Quan ${ }^{2}$, and Fang Liu ${ }^{3}$ \\ ${ }^{1}$ Department of Psychiatry, The First Affiliated Hospital of Chongqing Medical University, Chongqing, China \\ ${ }^{2}$ Department of Neurology, The First Affiliated Hospital of Chongqing Medical University, Chongqing, China \\ ${ }^{3}$ Department of Psychiatry, The First Affiliated Hospital of Kunming Medical University, Kunming, China
}

\begin{abstract}
Objective The aim of this study was to find if systemic family therapy (SFT) does work in anxiety and depression with epilepsy in adolescents (ADAE).

Methods 104 adolescents with epilepsy, aged 13-20 years old, were included from December 2009 to December 2010, the enrolled patients were with anxiety [Hamilton Anxiety Scale (HAMA) score $\geq 14$ points] or depression [Hamilton Depression Scale (HAMD) score $\geq 20$ points]. The patients were randomly divided into the control group $(n=52)$ treated with antiepileptic drugs (AED) and the intervention group ( $\mathrm{n}=52$ ) undergone Systemic Family Therapy (SFT) as well as AED. The AED improvements, anxiety and depression scores, Social Support Rating Scale (SSRS), Family Assessment Device (FAD) and scale of systemic family dynamics (SSFD) were observed after 3-month treatment.

Results The frequencies of epileptic seizures in intervention group was decreased much more significantly than the control group (4.22 \pm 3.54 times/month vs. $6.20 \pm 5.86$ times/month, $\mathrm{p}=0.04)$; and the scores of anxiety $(9.52 \pm 6.28$ points vs. $13.48 \pm 8.47 \mathrm{points}, \mathrm{p}=0.01)$ and depression ( $13.86 \pm 9.17$ points vs. $18.89 \pm 8.73$ points, $\mathrm{p}=0.02)$ were significantly decreased than the control group; meanwhile, the family dynamics and family functions were significantly improved, and the social support was also increased $(\mathrm{p}<0.05)$.

Conclusion SFT combined with AEDs had better efficacies than AEDs alone, not only the frequency of epileptic seizures was decreased, but also the patients' anxiety and depression were improved, and the family dynamics, family functions and social support were improved.
\end{abstract}

Psychiatry Investig 2016;13(3):305-310

Key Words Adolescents with epilepsy, Anxiety, Depression, Systemic family therapy, Antiepileptic drug therapy.

\section{INTRODUCTION}

Anxiety and depression were the most common problems of mental health problems in adolescents with epilepsy, ${ }^{1,2}$ almost one-third of epilepsy patients suffer from depression and anxiety, which is similar to the prevalence of drug-refractory epilepsy, ${ }^{3}$ although they were common but frequently underdiagnosed $^{4}$ and their role in quality of life (QOL) is receiving increasing scrutiny. ${ }^{5}$ Moreover, some antiepileptic drugs (AEDs) have mood stabilizing and anxiolytic effects, while others may worsen psychiatric symptoms ${ }^{6}$ and its harms had obtained

Received: April 24, 2015 Revised: July 18, 2015

Accepted: July 20, 2015 Available online: November 19, 2015

$\triangle$ Correspondence: Xuefeng Wang, $\mathrm{MD}, \mathrm{PhD}$

Department of Neurology, The First Affiliated Hospital of Chongqing Medical University, No. 1 Friendship Road, Chongqing 400016, China Tel: +86-23-89012878, Fax: +86-23-89012878, E-mail: jlxfcn@126.com

(@) This is an Open Access article distributed under the terms of the Creative Commons Attribution Non-Commercial License (http://creativecommons.org/licenses/bync/3.0) which permits unrestricted non-commercial use, distribution, and reproduction in any medium, provided the original work is properly cited. attentions from the community. ${ }^{7-11}$ It has been confirmed that high scores of anxiety and depression are associated with occurrence of seizures in public places ${ }^{12}$ various factors among epilepsy, anxiety, depression, individuals, families and communities, as well as the internal factors of family dynamics, family functions, social support, anxiety and depression, were systemically interconnected, the changes of every components inside the system would lead to the changes of other components. Some study suggested that enhancing family and emotional supports and decreasing depression could promote the quality of patient with epilepsy, and instrumental support may play a role in decreasing anxiety. ${ }^{13}$ Epilepsy can be associated with profound physical, social and psychological consequences, ${ }^{14}$ and the Systemic Family Therapy (SFT) was one kind of group psychotherapy treatment established on the abovementioned associations and with families as the therapeutic units, ${ }^{15-17}$ through scientifically assessing the relevant circumstances of young people with epilepsy, it could establish stable 
and reliable good therapeutic relationships with the epileptic adolescents and their family members, then solve the problems targeting the whole family, fundamentally change the disordered family dynamics models, and evoke the concepts of new development, so that the effects possessed by the resources inside every member might be developed as much as possible. This study observed the effects of SFT, which was performed at the same time of AEDs treatment, on ADAE patients, aiming to explore the feasibilities and effectiveness of $\mathrm{SF}$ in intervening children's behavioral problems.

\section{METHODS}

\section{Subjects}

104 adolescents with epilepsy were diagnosed by clinics and EEG in the outpatient and inpatient of Epilepsy Center, Department of Neurology, the First Affiliated Hospital of Chongqing Medical University, from December 2009 to December 2010, all patients were assessed by the Hamilton Anxiety Scale (HAMA) and showed that the presence of clinically significant anxiety symptoms (HAMA score $\geq 14$ points) or the assessment of Hamilton Depression Scale (HAMD) showed the presence of clinically significant depression symptoms (HAMD score $\geq 20$ points). Inclusion criteria: 1 ) aged $13-20$ years old; 2 ) were receiving AEDs treatment, and the drug concentration was stable; 3) with junior high school and higher education, could read and express well; 4) the Wechsler Intelligence Scale (WISC-R) measured: IQ $\geq 90$ points; 5) informed and consented by the patients and their guardians. Exclusion criteria: 1) associated with other systems' diseases (heart and liver dysfunctions, hypertension, diabetes, etc.); 2) long-termly administrated antiepileptic drugs, antidepressants and antipsychotics drugs that would affect the nervous system besides antiepileptic drugs; 3) the Wechsler intelligence scale measured: IQ < $<0$ points; 4) with hearing loss or vision disorders; 5) with consciousness and status epilepticus; 6) with mental illness, such as schizophrenia, affective disorders, anxiety disorders, personality disorders and child-adolescent mental disorders, etc; 7) with histories of alcohol, drug abuse and psychoactive substances; 8 ) refused to participate by the patients or their guardians. This study was conducted in accordance with the declaration of Helsinki. This study was conducted with approval from the Ethics Committee of the First Affiliated Hospital of Chongqing Medical University. Written informed consent was obtained from all participants.

The 104 adolescent patients were randomly divided into the control group $(n=52)$ and the intervention group $(n=52)$, the control group was only applied AEDs, while the intervention group was added SFT on the basis of AEDs, the treatment period was 3 months.

\section{Research methods}

The basic clinical data and epileptic seizure characteristics of patients included were internalized, all patients were performed the psychological evaluations before and after the study: 1) HAMA: HAMA included 14 items, established by Hamilton in $1959,{ }^{18}$ and was one of scales those were widely used for the assessments of psychiatric doctors. 2) HAMD: HAMD was compiled by Hamilton in $1960,{ }^{19}$ widely used to assess the clinical depression status, this study used 24 items. 3) Social Support Rating Scale (SSRS): SSRS was compiled by Xiao in $1986,{ }^{20}$ including 3 dimensions, and a total of 10 items, to measure the individual's social relationships. 4) Family Assessment Device (FAD): this questionnaire contained 60 items, and the seven dimensions (problem solving, character, communication, emotional involvement, emotional reactions, behavior control and general features) constituted seven subscales. ${ }^{21} 5$ ) scale of systemic family dynamics (SSFD): SSFD was compiled and revised by Kang ${ }^{22}$ and Yang, ${ }^{23}$ based on the Heidelberg family dynamic theory, and was the only localized family dynamics. The revised scale used 29 items and 4 dimensions to reflect the family dynamic characteristics. The 4dimensions included family atmosphere (including item: 3 , $7,8,15,16,18,20,22,25,28,19$ ), personalization (including item: $1,2,5,10,13,24,27,30$ ), system logic (including item: $6,11,12,14,19,21$ ) and disease concepts (including item: 9 , $17,23,26)$.

\section{SFT intervention measurements}

The intervention was performed once every half month, with a total of six times, and each time was $80 \mathrm{~min} .{ }^{24}$ The specific procedures were as follows: 1) beginning process (once): tasks: introduced STF and its purpose, secret-keeping commitment, explored the native upbringing experience and family background, assessed family functions, family dynamics and social support, psychological assessment, and arranged the treatment goals. 2) in-depth process (4 times): investigated the differences and interactions of family behaviors $\rightarrow$ positively assigned its meaning, and orientated the resources $\rightarrow$ "de-diagnose" $\rightarrow$ investigated the dynamics of changes $\rightarrow$ investigated the targets of changes $\rightarrow$ promoted the changes. Homework: "merit bombing"; recorded the "secret red tent"; "role-playing"; I could change to "72" kinds. 3) ending process (once): strengthened the changes, evaluates, reviewed and feedback.

\section{Study endpoint}

1) Scale assessment: HAMA, HAMD, SSRS, FAD, SSFD. 2) self-assessment: self-fulfilling prophecy during the treatment process (I could change to " 72 " kinds), recorded the secret red tent. 3) observation by others and self-evaluation: recorded 
self-changes observed by other family members, as well as good changes mutually observed among family members.

\section{Statistical analysis}

The baseline characteristics of the two groups were performed the chi-square test and $\mathrm{t}$-test for the comparisons among various dimensions; the questionnaire score used the paired $t-$ test to evaluate the changes before and after treatment, meanwhile, the scores of various scales (dimensions) between the two groups after treatment used the independent sample $t$ test to evaluate the differences of results between the two groups after treatment, with $\mathrm{p}<0.05$ considered as the statistical significance.

\section{RESULTS}

\section{General information}

Age, sex and education degree between the 2 groups had no significant difference ( $p>0.05$ ), and duration of epilepsy, seizure frequency, seizure type and medication form between the 2 groups showed no significant difference ( $p>0.05$ ) (Table 1).

\section{Comparison of seizure frequencies and scale scores between the 2 groups before and after treatment}

The baseline seizure frequencies, scores of anxiety and depression, family dynamics, family functions and SRS between the two groups showed no significant difference before treatment. At the end of treatment, the results showed that only seizure frequency of the control group was decreased than that before treatment, while the intervention group showed not only the significantly decreased seizure frequency, but also the significantly decreased scores of anxiety and depression, while family dynamics, family functions SRS were improved (Table 2).

\section{DISCUSSION}

This study found that the seizure frequency of the control group was significantly decreased after treatment $(p<0.05)$, indicating the effects of AEDs in treating epilepsy alone, consistent with the literatures. ${ }^{25,26}$ This study also found that compared with the control group, the seizure frequency of the intervention group was decreased much more significantly, and the difference was statistically significant $(\mathrm{p}<0.05)$, indicating that the efficacies of AEDs combined with SFT were much better than single AED in controlling seizures. ${ }^{27}$

Meanwhile, the scores of anxiety and depression of the intervention group were significantly lower than those in the control group, and the reasons might include: 1) the decreased seizure frequencies of adolescents with epilepsy made the patients' fears and tensions towards the disease eased; $;{ }^{28}$ ) the family dynamic characteristics, family functions and social support were changed. The alleviation of anxiety was related with the improvements of family sentiments, as well as the increased democracy, openness and subjective support of family behaviors; the alleviation of depression was related with the improvements of family sentiments, the increased subjective support, and the transition of behavioral control from severity

Table 1. Comparison of pre-test between the control group and the intervention group

\begin{tabular}{|c|c|c|c|c|}
\hline Comparison project & Control group $(\mathrm{N}=52)$ & Intervention group $(\mathrm{N}=52)$ & $\chi^{2} / t$ & $\mathrm{p}$ \\
\hline Male (N, \%) & $25,48.08 \%$ & $26,50.00 \%$ & 0.038 & 0.844 \\
\hline Age & $16.98 \pm 2.06$ & $17.14 \pm 1.82$ & 0.42 & 0.68 \\
\hline Disease course & $6.59 \pm 5.60$ & $5.38 \pm 5.00$ & 1.16 & 0.25 \\
\hline Education degree & - & - & 0.971 & 0.325 \\
\hline Junior high school and lower & 31 & 26 & - & - \\
\hline High school and higher & 21 & 26 & - & - \\
\hline Seizure type & - & - & 0.042 & 0.838 \\
\hline $\begin{array}{l}\text { Generalized tonic-clonic seizure+ } \\
\text { complex partial seizure }\end{array}$ & 34 & 33 & - & - \\
\hline Other seizure types & 18 & 19 & - & - \\
\hline Seizure form & - & - & 0.041 & 0.839 \\
\hline Single seizure & 32 & 33 & - & - \\
\hline$\geq 2$ seizure forms & 20 & 19 & - & - \\
\hline Medication & - & - & 0.038 & 0.844 \\
\hline Monotherapy & 27 & 26 & - & - \\
\hline Combined therapy & 25 & 26 & - & - \\
\hline
\end{tabular}


to democracy. ${ }^{29}$ The study also found that anxiety and depression interacted, and exhibited the parallel relationships. ${ }^{30}$

Thirdly, this study found that the family dynamics, family functions and social support of the intervention group had changed, among which the family functions of the intervention group were significantly improved, ${ }^{31}$ and the communication among family members was clear and effective, the role-division was clear, with mutual acceptance, appropriate emotional responses and clear boundary, so that the problemsolving skills were improved, and the execution of family tasks was enhanced, the abilities of adapting the changes when the tasks changed were improved. It was also found during the intervention process that the parental modes of rearing epileptic teenagers changed a lot, the emotional comfort from parents was increased, while the excessive interference, rejection and punishments were reduced, therefore the family environments were improved, the communication ways between young people with their parents were changed, and the patients' life qualities were significantly improved. This study found that the overall social support, material and financial support, subjectively-felt support and utilization rates towards various sup- ports of the intervention group were significantly increased, indicating that SFT increased the overall social support towards the adolescents with epilepsy, and the patients subjectively felt that they were more understood, as well as morally respected and supported. ${ }^{32}$

In addition, the control group also showed some changes of family dynamics, family functions and social support before and after treatment, the system logic, overall functions, behavior control, emotional reactions and problem solving all developed towards positive directions, while the family atmosphere, individualization, disease concepts, emotional involvement, roles, communications and total score of family functions were deteriorated towards the worse directions, which further validated the family theory, crisis theory and Josselson separation-individualization theory, indicating that the ADAE's abilities of family self-regulation and repairing were limited, therefore the SFT intervention was necessary. ${ }^{33}$

This study showed that if the seizure frequency was decreased, anxiety and depression were relieved, the family atmosphere would be pleasant and relaxed, the mutual understanding, mutual respect and mutual relations among family

Table 2. Comparison of seizure frequency and scale scores between the 2 groups

\begin{tabular}{|c|c|c|c|c|}
\hline \multirow{2}{*}{ Comparison project } & \multicolumn{2}{|c|}{ Control group $(\mathrm{N}=52)$} & \multicolumn{2}{|c|}{ Intervention group $(\mathrm{N}=52)$} \\
\hline & Baseline & Endpoint & Baseline & Endpoint \\
\hline Seizure frequency & $7.00 \pm 6.85$ & $6.20 \pm 5.86^{*}$ & $6.50 \pm 6.77$ & $4.22 \pm 3.54^{* \dagger}$ \\
\hline Hamilton Anxiety Scale & $13.76 \pm 8.76$ & $13.48 \pm 8.47$ & $13.41 \pm 7.83$ & $9.52 \pm 6.28^{* \dagger}$ \\
\hline Hamilton Depression Scale & $20.35 \pm 9.55$ & $18.89 \pm 8.73$ & $22.55 \pm 9.76$ & $13.86 \pm 9.17^{* \dagger}$ \\
\hline Scale of systemic family dynamics & - & - & - & - \\
\hline Family atmosphere & $28.70 \pm 12.02$ & $29.37 \pm 11.82$ & $25.78 \pm 11.29$ & $19.83 \pm 7.30^{* \dagger}$ \\
\hline Individuation & $20.80 \pm 9.19$ & $20.83 \pm 8.58$ & $19.53 \pm 7.57$ & $17.21 \pm 6.55^{* \dagger}$ \\
\hline Disease concepts & $11.33 \pm 3.36$ & $11.41 \pm 3.26$ & $11.69 \pm 3.90$ & $8.76 \pm 3.48^{* \dagger}$ \\
\hline System logic & $11.93 \pm 4.31$ & $12.78 \pm 4.91$ & $12.05 \pm 5.01$ & $13.67 \pm 6.30^{* \dagger}$ \\
\hline Family Assessment Device & - & - & - & - \\
\hline General functions & $19.33 \pm 7.46$ & $18.91 \pm 7.12$ & $19.03 \pm 7.17$ & $17.59 \pm 5.10^{*}$ \\
\hline Behavior control & $18.15 \pm 6.46$ & $18.37 \pm 6.25$ & $17.36 \pm 5.31$ & $13.69 \pm 3.17^{* \dagger}$ \\
\hline Emotional involvement & $12.98 \pm 4.84$ & 13.305 .46 & $12.19 \pm 3.60$ & $10.79 \pm 2.88^{* \dagger}$ \\
\hline Emotional reactions & $12.93 \pm 4.76$ & $12.50 \pm 4.41$ & $12.19 \pm 3.60$ & $10.83 \pm 3.56^{* \dagger}$ \\
\hline Character & $19.37 \pm 7.45$ & $19.72 \pm 6.37$ & $18.93 \pm 6.61$ & $17.40 \pm 5.25^{*}$ \\
\hline Problem Solving & $12.93 \pm 4.76$ & $12.79 \pm 4.21$ & $11.95 \pm 3.17$ & $11.19 \pm 3.13^{* \dagger}$ \\
\hline Communication & $18.48 \pm 7.05$ & 18.527 .45 & $16.43 \pm 4.90$ & $13.33 \pm 4.29 *+$ \\
\hline Total Family functional scores & $94.98 \pm 22.40$ & $100.85 \pm 19.75$ & $94.81 \pm 13.58$ & $90.91 \pm 17.71^{*+}$ \\
\hline Social Support Rating Scale & - & - & - & - \\
\hline Total score of Social support & $34.83 \pm 11.53$ & $34.52 \pm 9.97$ & $31.34 \pm 12.97$ & $41.41 \pm 10.61^{*+}$ \\
\hline Objective support & $12.24 \pm 5.42$ & $12.61 \pm 5.03$ & $10.41 \pm 5.80$ & $13.90 \pm 4.99^{*}$ \\
\hline Subjective support & $16.67 \pm 6.38$ & $16.24 \pm 6.07$ & $15.05 \pm 6.87$ & $20.84 \pm 7.54^{* \dagger}$ \\
\hline Utilization of Support & $5.91 \pm 2.05$ & $5.80 \pm 1.89$ & $5.88 \pm 2.32$ & $6.67 \pm 2.43^{*}$ \\
\hline
\end{tabular}

Compared with the baseline of the same group, ${ }^{*} \mathrm{p}<0.05$; compared with the endpoint of the control group, ${ }^{\mathrm{t}} \mathrm{p}<0.05$ 
members, as well as social supports actually obtained and felt, would be increased, and these changes would also further promote the declining of seizures frequency, and vice versa. Therefore, the factors that caused the mood changes of ADAE were not isolated and static, but interrelated, dynamic and causeeffect circulated; they were not linear, while formed a ringfeedback process, interrelated, mutually restricted and mutually influenced, the SFT intervention was feasible and effective towards ADAE. ${ }^{34}$

In summary, SFT theory and techniques were the main reasons towards the remarkable results achieved in this study, the therapists should establish stable and good therapeutic relationships with the epileptic youth and their family members on the basis of maintaining "neutrality". At the same time, the patients should not be considered as the family troublemakers, on the contrary, they were just the bearers, expressors and victims of "system problems", the treatments should not target the inner conflicts and personality traits of individuals, but should actively look for the breaking points of "disturbance" from the view of family. Finally, this study introduced the system theory, information theory and cybernetics to induce "the second level change" of families, namely fundamentally changed the disordered family dynamics model; the intervention targeted directly towards the rigid, aging, or invalid family structures and disordered family relationships, used the differentiated questioning, circulation questioning, feedforward questioning, alteration and explanation, symptom prescriptions, positive meaning assignment and homework to make the family behaviors re-assign their meanings, promote the family members to change the family "rules", improve their family dynamics, family functions, family relationships and social support, thus encouraging every member to develop the effects possessed by the resources inside them as much as possible

\section{Acknowledgments}

This work was supported by Science and Technology research project of Chongqing Municipal Educational Commission (No. KJ080322), the project of Chongqing Municipal Health Bureau (No. 2010-2-015), the project of Chongqing Education and Science topics (No. 2012-GX-123), and the project of Medical research topics of Chongqing Municipal Health Bureau (No. 2013-2-033).

\section{REFERENCES}

1. Reilly C, Agnew R, Neville BG. Depression and anxiety in childhood epilepsy: a review. Seizure 2011;20:589-597.

2. Jackson MJ, Turkington D. Depression and anxiety in epilepsy. J Neurol Neurosurg Psychiatry 2005;76(Suppl 1):i45-i47.

3. Kwon OY, Park SP. Depression and anxiety in people with epilepsy. J Clin Neurol 2014;10:175-188.

4. Drinovac M, Wagner H, Agrawal N, Cock HR, Mitchell AJ, von Oertzen TJ. Screening for depression in epilepsy: a model of an enhanced screening tool. Epilepsy Behav 2015;44:67-72.

5. Jacoby A, Snape D, Lane S, Baker GA. Self-reported anxiety and sleep problems in people with epilepsy and their association with quality of life. Epilepsy Behav 2015;43:149-158.

6. Moseley BD, Cole D, Iwuora O, Strawn JR, Privitera M. The effects of lacosamide on depression and anxiety in patients with epilepsy. Epilepsy Res 2015;110:115-118.

7. Lai CO. Anxiety and depression in children with epilepsy. Neurol Asia 2013;18:39.

8. Stevanovic D, Jancic J, Lakic A. The impact of depression and anxiety disorder symptoms on the health-related quality of life of children and adolescents with epilepsy. Epilepsia 2011;52:e75-e78.

9. Cushner-Weinstein S, Dassoulas K, Salpekar JA, Henderson SE, Pearl PL, Gaillard WD, et al. Parenting stress and childhood epilepsy: the impact of depression, learning, and seizure-related factors. Epilepsy Behav 2008;13:109-114.

10. Gar NS, Hudson JL. An examination of the interactions between mothers and children with anxiety disorders. Behav Res Ther 2008;46:12661274.

11. Devylder JE, Gearing RE. Declining social support in adolescents prior to first episode psychosis: associations with negative and affective symptoms. Psychiatry Res 2013;210:50-54.

12. Siqueira NF, Oliveira FL, Siqueira JA, Souza EA. In adolescents with epilepsy, high scores of anxiety and depression are associated with occurrence of seizures in public places. Arq Neuropsiquiatr 2015;73:205-211.

13. Wang YH, Haslam M, Yu M, Ding J, Lu Q, Pan F. Family functioning, marital quality and social support in Chinese patients with epilepsy. Health Qual Life Outcomes 2015;13:10.

14. S RP, Ramesh R, Rachel P, Chanda R, Satish N, Mohan VR. Quality of life among people with epilepsy: a cross-sectional study from rural southern India. Natl Med J India 2012;25:261-264.

15. Grabowska-Grzyb A, Jedrzejczak J, Naganska E, Fiszer U. Risk factors for depression in patients with epilepsy. Epilepsy Behav 2006;8:411-417.

16. Roeder R, Roeder K, Asano E, Chugani HT. Depression and mental health help-seeking behaviors in a predominantly African American population of children and adolescents with epilepsy. Epilepsia 2009; 50:1943-1952.

17. Turky A, Beavis JM, Thapar AK, Kerr MP. Psychopathology in children and adolescents with epilepsy: an investigation of predictive variables. Epilepsy Behav 2008;12:136-144.

18. Hamilton M. The assessment of anxiety states by rating. Br J Med Psychol 1959;32:50-55.

19. Hamilton M. A rating scale for depression. J Neurol Neurosurg Psychiatry 1960;23:56-62.

20. Xiao SY. Theory and application of Social Support Rating Scale. J Clin Psychiatry 1994;4:98-100.

21. Epstein NB, Baldwin LM, Bishop DS. The Mcmaster family assessment device. J Marital Fam Ther 1983;9:171-180.

22. Kang C. The questionnaire of systemic family dynamics: development, reliability and validity. Chinese Ment Health J 2001;15:92-95.

23. Yang JZ, Kang CY, Zhao XD. The self-rating inventory of systematic family dynamics: development, reliability and validity. Chinese J Clin Psychol 2002;10:263-265.

24. Pote H, Stratton P, Cottrell D, Shapiro D, Boston P. Systemic family therapy can be manualized: research process and findings. J Fam Ther 2003;25:236-262.

25. Ekinci O, Titus JB, Rodopman AA, Berkem M, Trevathan E. Depression and anxiety in children and adolescents with epilepsy: prevalence, risk factors, and treatment. Epilepsy Behav 2009;14:8-18.

26. Hoppe C, Elger CE. Depression in epilepsy: a critical review from a clinical perspective. Nat Rev Neurol 2011;7:462-472.

27. Gebauer-Bukurov K, Markovic J, Sekulic S, Bozic K. Social competence among well-functioning adolescents with epilepsy. Epilepsy Behav 2015;42:54-60.

28. Cianchetti C, Messina P, Pupillo E, Crichiutti G, Baglietto MG, Veggiotti $\mathrm{P}$, et al. The perceived burden of epilepsy: impact on the quality of life of children and adolescents and their families. Seizure 2015;24:93-101. 
29. Carbone L, Plegue M, Barnes A, Shellhaas R. Improving the mental health of adolescents with epilepsy through a group cognitive behavioral therapy program. Epilepsy Behav 2014;39:130-134.

30. Semah F, Thomas P, Coulbaut S, Derambure P. Early add-on treatment vs alternative monotherapy in patients with partial epilepsy. Epileptic Disord 2014;16:165-174.

31. Baker GA, Spector S, McGrath Y, Soteriou H. Impact of epilepsy in adolescence: a UK controlled study. Epilepsy Behav 2005;6:556-562.

32. Champaloux SW, Young DR. Childhood chronic health conditions and educational attainment: a social ecological approach. J Adolesc Health 2015;56:98-105

33. Schultz RJ. Parental experiences transitioning their adolescent with epilepsy and cognitive impairments to adult health care. J Pediatr Health Care 2013;27:359-366.

34. Dehn LB, Korn-Merker E, Pfafflin M, Ravens-Sieberer U, May TW. The impact on family scale: psychometric analysis of long and short forms in parents of children with epilepsy. Epilepsy Behav 2014;32:21-26. 